\title{
FRATURA DE PÊNIS
}

\section{PENILE FRACTURE}

\section{Leonardo de Souza Alves, TCBC-MG ${ }^{1}$}

\begin{abstract}
RESUMO: Objetivo: Analisar as circunstâncias, o diagnóstico, o tratamento e a evolução dos pacientes com fratura de pênis. Método: Foram acompanhados 19 pacientes no período de 1999 à 2003 com diagnóstico de fratura de pênis. Resultados: Quinze pacientes submetidos ao procedimento cirúrgico nas primeiras 48 horas evoluiram bem. Os demais quatro pacientes que foram submetidos ao tratamento clínico, por diversos fatores, evoluiram com deformidade peniana. Conclusão: Afecção que ocorre somente quando o pênis encontra-se em ereção, o tratamento cirúrgico precoce é o que demonstra melhores resultados, com preservação da função erétil (Rev. Col. Bras. Cir. 2004; 31(5): 284-286) - ISSN 0100-6991.
\end{abstract}

Descritores: Fratura; Pênis; Disfunção erétil; Trauma.

\section{INTRODUÇÃO}

A fratura de pênis (FP), é definida como trauma peniano fechado, com ruptura da túnica albugínea, camada de tecido fibroso que envolve os corpos cavernosos e esponjoso localizada logo abaixo da pele do pênis. Esta ruptura è consequente ao aumento de pressão sob a albugínea, em geral durante atividade sexual, quando sua espessura se reduz em até $75 \%$, tornando-se mais frágil e susceptível ao rompimento ${ }^{1-4}$. Este ocorre, na maioria das vezes, na região da base do pênis e permite a saída, sob grande pressão, do volume sanguíneo acumulado no pênis. Neste momento o pênis perde o estado de ereção tornando-se flácido, com grande hematoma e deformação (Figura 1).

Pode ocorrer uretrorragia ou hematúria microscópica, caso o rompimento tenha alcançado o corpo esponjoso que circunda a uretra, o que pode acontecer em 10 a $20 \%$ dos casos $^{1}$. O diagnóstico da FP é eminentemente clínico. Métodos de imagem são utilizados para localizar com precisão o ponto da lesão. No nosso meio o ultra-som com doppler é o mais utilizado, demonstrando o exato local da fratura ${ }^{2}$. A ressonância nuclear magnética, é o método diagnóstico "padrão ouro". O tratamento preconizado é a abordagem cirúrgica nas primeiras 48 horas, associado à administração de antiinflamatórios e resfriamento do pênis ${ }^{1-6}$. O uso de ansiolíticos também pode ser necessário, uma vez que esses pacientes procuram os serviços de urgência muito ansiosos com a possibilidadde de uma futura impotência sexual. O tratamento cirúrgico realizado nas primeiras 48 horas tem demonstrado em vários estudos, um retorno à atividade sexual de forma mais rápida e sem curvatura peniana ${ }^{1-6}$, a qual ocorre, em geral, nos pacientes que não foram submetidos à cirurgia $^{3}$.

\section{MÉTODO}

Foram acompanhados 19 pacientes vítimas de fratura de pênis (FP) no período de 1999 a 2003. Quinze destes

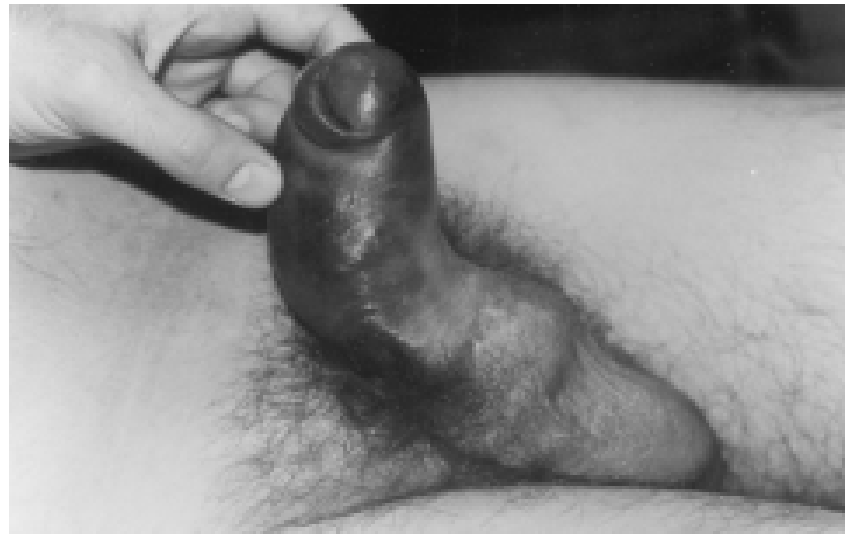

Figura 1 - Fratura Peniana; pênis deformado, com grande hematoma.

pacientes $(78,94 \%)$ procuraram o serviço de urgência nas primeiras 48 horas do trauma e foram submetidos à propedêutica pré-peratória e cirurgia, com rafia primária da lesão, além de antiinflamatórios e resfriamento local. Os demais quatro pacientes que nos procuraram com tempo superior à 72 horas do acidente foram submetidos à tratamento clínico (antiinflamatórios, gêlo local e abstinência sexual ). Todos foram orientados à retornar após 60 dias com o relato das primeiras atividades sexuais.

Todos os 15 pacientes operados, foram submetidos à bloqueio anestésico, a não ser um paciente que, devido à quadro neurológico, foi submetido à anestesia geral. Foi realizada incisão subcoronal e desenluvamento do pênis (descolamento da pele do pênis) até o púbis, punção de um dos corpos cavernosos com "butterfly"e infusão contínua de soro fisiológico até atingir o estado de ereção, momento no qual localizava-se o ponto de fratura pelo estravazamento do soro. Após desbridamento da lesão era realizada rafia primária com fio absorvível 3.0 com pontos embutidos e reconstituição da pele do pênis até o sulco coronal. Curativo compressivo e, em alguns casos, cateterismo vesical de demora.

1. Titular da Sociedade Brasileira de Urologia; Diretor - Procriar - Instituto de Urologia - Andrologia e Pesquisa na Reprodução Humana.

Trabalho realizado no Procriar - Instituto de Urologia - Andrologia e Pesquisa na Reprodução Humana, Belo Horizonte - Minas Gerais - Brasil. 


\section{RESULTADOS}

Do total de 19 pacientes acompanhados pelo serviço, nove $(47,36 \%)$ apresentaram lesão de corpo cavernoso isolada, cinco $(26,31 \%)$ lesão de corpo esponjoso e dois $(10,52 \%)$ lesão associada de corpos cavernoso e esponjoso. Em três pacientes $(15,78 \%$ ) não foi possível identificar a lesão (Tabela 1). Nos pacientes submetidos ao tratamento cirúgico da lesão nas primeiras 48 horas não se observou curvatura peniana ou mínima alteração em relação ao aspecto anterior. Os quatro pacientes submetidos à observação clínica, e que foram os primeiros da casuística, evoluíram com curvatura homolateral à lesão, diminuíção da qualidade da ereção e formação de calo ósseo. Estão aguardando tratamento cirúrgico tardio, para correção da curvatura. As atividades sexuais foram liberadas aos pacientes operados, após 60 dias da intervenção cirúrgica, quando foram orientados a retornarem para o controle. Não houve queixas em relação ao resultado final do tratamento cirúrgico.

\section{DISCUSSÃo}

A fratura de pênis é uma afecção pouco usual nos serviços de urgência de urologia, mas não rara. Grande parte desses pacientes é atendido em caráter de urgência, ou seja, no momento do trauma. Provalvelmente, o número de casos não notificados é maior, devido à vergonha, falta de orientação, ou situações comprometedoras! Na maioria dos casos ocorre durante o intercurso sexual com a parceira em posição sobre o parceiro, quando existe uma força física maior sobre a base do pênis, ou então quando durante a penetração o pênis sai da vagina e em seu retorno não encontra o orifício vaginal. Muitos pacientes informam ouvir um estalido da fratura no momento da lesão. A fratura peniana pode ocorrer também, conforme relato de pacientes, durante a masturbação ou "rolling on the bed", quando o paciente na fase REM ( rapid eye moviment ) do sono, entra em ereção peniana e rola na cama sobre o pênis ocasionando o traumatismo ${ }^{3,7}$.O aumento da pressão em qualquer ponto da túnica albugínea, fragilizada pela diminuição da sua espessura devido o estado de ereção, é apontado como a causa da fratura. Pode-se concluir, portanto, que todos os homens, teoricamente, estão sujeitos à esse tipo de trauma ${ }^{2-5}$. Na nossa observação $68,42 \%$ dos traumatismos ocorreram durante o intercurso sexual normal. Em $15,78 \%$ dos pacientes durante o sono e $15,78 \%$ durante a masturbação (Tabela 2).

O diagnóstico da FP é feito pela história clínica e exame físico na maioria das vezes. Pode-se utilizar a ultra-
Tabela 1 - Localização das lesões no pênis.

\begin{tabular}{lcc}
\hline Localização & número & \% \\
\hline Corpo cavernoso & 09 & 47,36 \\
Corpo esponjoso & 05 & 26,31 \\
Associada c+e & 02 & 10,52 \\
Não identificada & 03 & 15,78 \\
\hline
\end{tabular}

Fonte: Procriar - Instituto de Urologia e Andrologia - Belo Horizonte - $M G$.

Tabela 2 - Etiologia das lesões.

\begin{tabular}{lcc}
\hline Causas & número & $\%$ \\
\hline Relação Sexual & 13 & 68,42 \\
"Rolling on Bed" & 03 & 15,78 \\
Masturbação & 03 & 15,78 \\
\hline Fonte: Procriar - Instituto de Urologia e Andrologia & Belo Horizonte \\
- MG. &
\end{tabular}

sonografia que demonstra área de descontinuidade na túnica albugínea. A ressonância nuclear magnética é o método diagnóstico pré-operatório mais fidedigno, mas seu alto custo ainda dificulta a sua realização. Em alguns casos pode-se utilizar a cavernosografia, através da injeção de contraste iodado no corpo cavernoso e observação do extravasamento no local da fratura. No entanto, resultados falso negativos, devido o tamponamento do ponto de fratura com o sangue extravasado, limitam o exame. O método mais acessível e mais barato, é a infusão de soro fisiológico no corpo cavernoso durante o procedimento cirúrgico, que permite a localização precisa do vazamento de soro, e o pronto tratamento da fratura ${ }^{4}$. A presença de hematúria ou uretrorragia sugere maior gravidade da lesão,com trauma sobre o corpo esponjoso e consequente lesão uretral ${ }^{4}$. Esta lesão pode evoluir para estenose uretral ou se acompanhar de um quadro grave de Síndrome de Fournier, devido infiltração de urina infectada.

Dependendo da gravidade da lesão deve-se inclusive drenar a urina por punção supra púbica. Atualmente o tratamento através de cirurgia nas primeiras 24 horas é o mais aceito ${ }^{1-7}$. Apresenta melhores resultados ao se comparar com a conduta expectante, fato observado em nossa casuística, onde os pacientes não operados desenvolveram curvatura da haste peniana. A cirurgia precoce além do alívio ao paciente diminui bastante o risco de curvatura peniana e infecção.

\footnotetext{
ABSTRACT

Background: To analize the ethiology, diagnosis, treatment and evolution of patients with penile fracture. Method: We analysed 19 pacients with penile fracture diagnosis between 1999 and 2003. Results: Fifteen patients were submitted to surgical therapy within the first 48 hours with good results. Four patients developed penile curvature on follow up. Conclusions: Surgical therapy showed better results with erectile function preserved.
}

Key words: Fracture; Penis; Erection disfunction; Trauma. 


\section{REFERÊNCIAS}

1. Bertero EB, Campos RS, Mattos D - Penile fracture with urethral injury. Int Braz J Urol, 2000, 26(3):295-297.

2. Costa M, Alves LS, Bamberg A, et al. - Fratura de pênis - A utilidade do ultra-som no diagnóstico. Congresso Brasileiro de Urologia, 37, 1999, Rio de Janeiro. Tema livre n. 671.

3. Alves LS, Costa M, Bamberg A - Fratura de pênis. 11 casos atendidos no HFR em 1998. Congresso Brasileiro de Urologia, 37, 1999, Rio de Janeiro. Tema livre n.726,

4. Jonathan G - "Surgery of penis and urethra". In Walsh P, Retik A, Vaughan D, et al. Campbell's Urology. $7_{\text {th }}$ Edition. Saunders Company, vol 3, 1998, pp. 3376-3377.

5. Alves LS, Mello CV - Fratura de pênis: apresentação de caso. Rev Méd Minas Gerais, 2002, 12(1):55-56.
6. Aguiar W - Fratura de pênis. Sinopse de Urologia 1999, 3(3): 51-52.

7. Koifman L, Cavalcanti AG, Manes CH, et al. - Fratura peniana. Experiência em 56 casos. Int Braz J Urol, 2003, 29(1):35-37.

Endereço para correspondência:

Leonardo de Souza Alves

Procriar - Instituto de Urologia - Andrologia \& Pesq. Reprod. Humana R. Gonçalves Dias, 142 conj. 310 / 313 - Funcionários

Belo Horizonte - M.G.

CEP: 30140-090

Fone: (31) 3225-0907

E-mail:procriar@bol.com.br 